\title{
O DIREITO FUNDAMENTAL À ENVELHECER COM DIGNIDADE
}

\section{THE FUNDAMENTAL RIGHT TO GROW OLD WITH DIGNITY}

\author{
${ }^{1}$ Camila Rabelo de Matos Silva Arruda \\ ${ }^{2}$ Leticia Maria de Oliveira Borges
}

\section{RESUMO}

Ao longo dos anos o papel do idoso na sociedade vem mudando consideravelmente, a população está envelhecendo e aumentando a expectativa de vida. A Lei $n^{\circ}$ 10741/03 que estabeleceu o Estatuto do Idoso, onde o legislador buscou assegurar o direito de envelhecer com dignidade. $\mathrm{O}$ aumento do número de aposentados e do desemprego, gerou a demanda de alteração ao sistema previdenciário, que está em tramitação no congresso nacional. Este artigo, então, faz a análise da forma como a sociedade vem tratando o idoso e se preparando para lidar com o envelhecimento da população.

Palavras-chaves: Envelhecimento; Previdência Social; Violação de Direitos; Idoso; Dignidade da Pessoa Humana.

\begin{abstract}
Over the years the role the growing old in society has been changing considerably, the population is aging and increasing life expectancy. Law No. 10741/03, which established the Statute of the Elderly, where the legislator sought to ensure the right to grow old with dignity. The increase in the number of retirees and unemployment generated changing the demand in the social security system, which is being processed at the national congress. This article examines how society has been treating the elderly and preparing to deal with the aging population.
\end{abstract}

Keywords: Aging; Social Security; Violation of Rights; Elderly; Dignity of Human Person.

\footnotetext{
1 Mestra e Doutoranda, Professora da Universidade Veiga de Almeida, UVA, Rio de Janeiro, (Brasil). Especialista em Administração Pública pela Fundação Getulio Vargas - FGV, Rio de Janeiro, (Brasil). Membro do Grupo de Pesquisa reconhecido pela UVA no CNPq e do CONPEDI. E-mail: camilapmbr@ig.com.br

2 Mestra e Doutoranda em Direito, Professora da Universidade Veiga de Almeida, UVA, Rio de Janeiro, (Brasil). Especialista em Direito pela Universidade Gama Filho - UGF Rio de Janeiro, (Brasil). Membro de Pesquisa reconhecido pela UVA no CNPq. CONPEDI. E-mail: ticha_borges@yahoo.com.br
} 


\section{INTRODUÇÃO}

Envelhecer significa a ação natural do tempo que faz com que todo ser vivo envelheça, alterando sua aparência física, bem como as funcionalidades do seu corpo que passam a ser mais precárias.

Nas últimas décadas, no Brasil, houve um aumento considerável na expectativa de vida, tornando a população mais idosa ${ }^{3}$.

A inquietação concernente aos mitos que cercam o envelhecer numa sociedade, onde ser jovem é um imperativo, trazendo com isto, uma cultura na qual a beleza física, um corpo bem rijo e definido, é quem vai ditar as posições nos grupos sociais levando os sujeitos a corridas desenfreadas em busca de elixires da longevidade, tratamentos rejuvenescedores, academias, cirurgias e afins; e, associado a isso, o desenvolvimento de patologias e distúrbios psicológicos quando se sentem excluídos deste contexto ou quando apesar de incluídos os resultados nunca são plenamente satisfatórios.

O papel do idoso na sociedade vem mudando consideravelmente ao longo dos anos, com o envelhecimento da sociedade e com o aumento da expectativa de vida que aumentou consideravelmente ao longo das últimas décadas ${ }^{4}$. Com o envelhecimento, houve a necessidade de desconstruir os mitos estabelecidos pela sociedade, para isso devem ser consideradas as mudanças sociais, culturais, psicológicas, bem como a melhoria da qualidade de vida que interferiu diretamente nos aspectos biológicos do envelhecimento.

Com o advento da Lei ${ }^{\circ}$ 10741/03 que estabeleceu o Estatuto do Idoso, houve uma preocupação do legislador em assegurando o direito de envelhecer com dignidade.

$\mathrm{O}$ aumento do número de $\operatorname{aposentados}^{5}$ fez com que a previdência se tornasse um desafio para os administradores, com a inversão da pirâmide etária e o aumento do desemprego no país, houve uma nova demanda de alteração ao sistema previdenciário, que está em tramitação no congresso nacional, visando aumentar a idade para aposentadoria, visando manter a saúde dos fundos previdenciários.

\footnotetext{
${ }^{4}$ http://www.ibge.gov.br/apps/populacao/projecao/ (acesso em 19/08/2016)

5 http://www.ibge.gov.br/apps/populacao/projecao/ (acesso em 19/08/2016)
} 
Uma análise se tornou necessária, a avaliar de que forma a sociedade vem tratando o idoso. A sociedade está se preparando para lidar com o envelhecimento da população.

O artigo 16 da Declaração dos Direitos $\mathrm{Humanos}^{6}$, que traduz a família como o núcleo natural e fundamental da sociedade, e é endossado no Estatuto do Idoso, que declara, em seu artigo $3^{\circ}$ :

"É obrigação da família, da comunidade, da sociedade e do Poder Público assegurar ao idoso, com absoluta prioridade, a efetivação do direito à vida, à saúde, à alimentação, à educação, à cultura, ao esporte, ao lazer, ao trabalho, à cidadania, à liberdade, à dignidade, ao respeito e à convivência familiar e comunitária."7

O presente trabalho visa verificar a representação social do envelhecimento e o cumprimento do direito fundamental de envelhecer com dignidade.

Visando entender de que forma ocorre o envelhecimento dentro da sociedade descrevemos os principais problemas enfrentados no processo de envelhecimento, buscamos verificar os aspectos biológicos, sociais, psicológicos do envelhecer. Buscamos analisar a contribuição da legislação federal para o envelhecimento com dignidade.

Para nos inserirmos melhor na realidade do cotidiano dos idosos faz-se necessário discriminar os aspectos sociais relevantes para assegurar o envelhecimento com dignidade.

O presente trabalho possui relevância social por tratar-se de um tema atual e de grande sensibilidade, pois envelhecer é um processo natural a todos os seres humanos.

Por mais que se crie, invente, repagine e revolucione quando o assunto é envelhecimento, o compositor Arnaldo Antunes, registrou em uma de suas composições intitulada "Envelhecer", que "a coisa mais moderna que existe nesta vida é envelhecer"8. Mesmo que muitos tentem evitar este inevitável momento, traremos uma discussão acerca da representação social do envelhecimento e suas possíveis repercussões psicológicas, para as pessoas que vivenciam o processo biológico de envelhecer.

1. Aspectos históricos do envelhecimento

\footnotetext{
${ }^{6}$ Declaração Univesal dos Direitos Humanos: “Art 16 (...) §2. A família é o núcleo natural e fundamental da sociedade e tem direito à proteção da sociedade e do estado.

"http://www.direitoshumanos.usp.br/index.php/Declara\%C3\%A7\%C3\%A3o-Universal-dos-Direitos-

Humanos/declaracao-universal-dos-direitos-humanos.html (acesso em 19/08/2016)

${ }^{7}$ http://www.planalto.gov.br/ccivil_03/leis/2003/L10.741.htm (acesso em 19/08/2016)

8 https://www.letras.mus.br/arnaldo-antunes/1547283/ (acesso em 19/08/2016)
} 
A velhice pode ser vista em de duas formas totalmente diferentes: a forma que é vista culturalmente, que pode ser mais ou menos valorizada, ou, a forma que é vista individualmente.

Schneider e Irigaray (2008) descreve que os idosos têm conseguido mudar seus padrões de vida ao longo das décadas, eles contribuem diretamente com a sociedade, trazem suas memórias e experiências, sem falar na contribuição na formação dos valores na família.

Historicamente, dentro da família, a autoridade do patriarca não diminuía com o tempo, os mais jovens deviam obediência aos mais velhos, e essa autoridade não poderia ser questionada. Os anciãos em algumas culturas eram considerados sábios, sendo inclusive consultados nas tomadas de decisão dos governantes.

Segundo Confúcio (apud Beauvoir, 1976, p. 102), a velhice traz com ela a sabedoria:

"Aos 15 anos, dedicava-se ao estudo da sabedoria; aos 30, nela me confirmei; aos 40 já não tinha dúvidas, aos 60 nada mais no mundo me poderia chocar; aos 70 podia seguir os ditames de meu coração sem transgredir a lei moral".

No Oriente a velhice não era apresentada como um flagelo, no Ocidente podemos encontrar escritos egípcios datados de 2500 antes de Cristo que descreviam a velhice como sendo penosa, e como declínio das condições físicas ao longo do tempo.

Em seus textos Ptah-Hotep (apud Beauvoir, 1976), filósofo e poeta descreve a velhice como sendo a pior desgraça que pode acometer um homem.

Cada sociedade trata a velhice de uma forma diferente, os valores dados aos idosos são influenciados por questões culturais, mas em tese, as reações sociais são as mesmas: observa-se o declínio das condições do organismo, e muitas vezes a tentativa de rejuvenescimento, ou a busca pelo não envelhecimento.

Na cultura judaica antiga, os anciãos eram considerados sábios, detentores de poder e sabedoria, a velhice é considerada uma virtude, na Bíblia Sagrada os anciãos são citados como sábios, aqueles que devem ser respeitados, no livro das Cartas de São Paulo a I Timóteos 5, 1-8, houve um chamamento aos cuidados e ao respeito com os idosos:

“Ao ancião não repreendas com aspereza, mas adverte-o como a um pai, mas adverte-o como a um pai, aos moços como a irmãos, às mulheres de idade como as mães, às jovens como as irmãs, com toda a pureza.

Honra as viúvas que são realmente viúvas. Se uma viúva tem filhos ou netos, como primeira obrigação aprendam estes a exercer com a 
própria família o dever da piedade filial e a retribuir aos pais o que deles receberam, porque isto é agradável aos olhos de Deus. Mas, a que verdadeiramente é viúva e desamparada, põe a sua esperança em Deus e persevera noite e dia em orações e súplicas.

Aquela, pelo contrário, que vive nos prazeres, embora viva está morta. Recorda-lhes isto, para que sejam irrepreensíveis.

Quem descuida dos seus, e principalmente dos de sua própria família, é um renegado, é pior que um infiel." (I Timóteo 5, 1-8)

No livro dos Números 11, 16-26, que pertence ao Pentateuco, (cinco principais livros do Antigo Testamento), descreve o idoso da seguinte forma:

"Junta-me setenta homens entre os anciãos de Israel, que sabes serem os anciãos do povo e tenham autoridade sobre ele. Conduze-os à tenda de reunião, onde estarão contigo. Então descerei e ali falarei contigo. Tomarei do espírito que está em ti e o derramarei sobre eles, para que possam levar contigo a carga do povo e não estejas mais sozinho." (Nm 11.16-26).

O filósofo Burckhart (apud Beauvoir, 1976) observou que entre os gregos, a velhice ocupa um lugar inteiramente especial no conjunto de queixas inspiradas na vida terrestre.

"Em Atenas, as leis de Sólon, entregavam todo o poder às pessoas de idade, enquanto se manteve os regimes aristocráticos e conservadores, a velha geração manteve suas prerrogativas. Quando se estabeleceu a democracia perderam essas prerrogativas. Suas autoridades ficaram arranhadas e enfraquecidas, com poucas demonstrações de respeito na vida particular".

$\mathrm{Na}$ Roma antiga as leis demonstraram a estreita relação entre a velhice e a estabilidade da sociedade. Parece ter havido um grande contraste entre os velhos da elite e o dos plebeus.

Segundo a visão de Plutarco (apud Beauvoir, 1976), filósofo grego, compara a velhice a um triste outono:

"Ora, dir-se-ia que o outono é a velhice do ano, ao cabo de sua revolução; pois a umidade ainda não chegou e o calor já se foi ou perdeu sua energia e - indício de frieza e secura - torna os corpos propensos e dispostos às doenças. Ora, porque deverá a alma participar e se ressentir das disposições do corpo e por que, estando os espíritos cristalizados e lassos, se ofusca a faculdade divinatória e se embaça, tal espelho coberto de névoa? (p.125)". 
Nessa visão filosófica podemos entender que a velhice era vista como sombria e triste.

O novo paradigma sobre o envelhecimento tem focado numa visão positiva, onde a velhice é encarada como sendo uma fase que não seja apenas de declínio, mas que pode ser uma fase de crescimento, onde se tem a oportunidade de viver experiências, se pode ter certa estabilidade, usufruindo de oportunidades que possam contribuir de forma positiva para o processo de envelhecimento, com uma visão do desenvolvimento psicológico no envelhecimento.

\section{Tipos de Envelhecimento}

Mais do que uma referência cronológica, Terceira Idade é uma expressão eleita para o tratamento das pessoas idosas. A velhice é uma etapa natural dos seres humanos que conseguem alcançá-lo; no ciclo natural da vida ocorre "o nascimento, crescimento, reprodução, envelhecimento e morte". Segundo a gerontologia, ciência que estuda do envelhecimento, o envelhecimento não significa a decadência, e sim uma sequência da vida, com suas peculiaridades e características (Almeida; Lourenço, 2007; Almeida; Lourenço, 2008).

Podemos observar que o envelhecimento não é um processo único, e sim uma soma de vários fatores, um processo que se inicia ao nascer e que perdurará até a morte, por mais que se queira retardar esse envelhecimento, o fato é que ele ocorrerá independente da própria vontade.

De acordo com Erikson (2011), são determinados oito estágios de desenvolvimento psicossocial e forças básicas, destaco o sexto" idade jovem adulta" que vai de 18 à 35 anos; sétimo " adulto" que vai de 35 à 55 anos e oitavo " maturidade e velhice" mais de 55 anos. Tais estágios se caracterizam por formas positivas e negativas de reagir: intimidade versus isolamento, generatividade versus estagnação, integridade versus desespero, respectivamente. O autor, ainda destaca, no último estágio como uma força básica a sabedoria.

O envelhecimento Cronológico é a modificação sofrida ao longo do tempo, caracterizado como um fenômeno biológico que atinge o ser humano. A idade cronológica refere-se somente ao número de anos que tem decorrido desde o nascimento da pessoa, portanto não é um índice de desenvolvimento biológico, psicológico e social, pois ela por si 
só não causa o desenvolvimento. Segundo Hoyer e Roodin (2003 apud Schieder e Irigaray), a idade é meramente um marcador aproximado do processo que influencia o comportamento ao longo do tempo.

O envelhecimento biológico ocorre ao longo dos anos e levam à velhice, permanecem desconhecidos ao longo dos anos, apesar das alterações com o avançar da idade sejam observáveis ou até mesmo sentidas (Orefice, 2007). O envelhecimento biológico gera a diminuição das reservas funcionais do organismo e a redução das funcionalidades de todos os aparelhos e sistemas: músculo, esquelético, nervoso central e periférico, cardiovascular, pulmonar, renal e endócrino.

A velhice humana origina reduções na capacidade funcional devido ao transcurso do tempo, como ocorre com qualquer organismo vivo, mas essas limitações não impossibilitam o ser humano de desenvolver uma vida plena como pessoa que vive, não somente com o físico, mas, sobretudo com o psíquico e o social (Moragas, 1997). O envelhecimento funcional pode ser precipitado por fatores que podem contribuir diretamente para o envelhecimento precoce: as condições de vida, condições de trabalho, qualidade dos transportes coletivos, remuneração, forma de comportamento, má alimentação, uso de drogas e sedentarismo. Às diferenças econômicas, políticas, sociais, culturais e, também às questões nacionais e regionais que também podem acarretar um envelhecimento precoce.

No contexto da saúde, Caneppele (2007), ressalta que a incapacidade se torna um termo mais abrangente, e que inclui "deficiências", "limitações às atividades" e "restrições à participação". Este termo denota os aspectos negativos da interação entre um indivíduo (com um estado ou condição de saúde) e os fatores contextuais do indivíduo (fatores ambientais e pessoas).

O envelhecimento individual depende do grau de fragilidade do organismo e do psiquismo. O envelhecimento representa a consequência ou os efeitos da passagem do tempo no organismo (envelhecimento somático) e psiquismo (envelhecimento psíquico) que ocorre de forma diferente em cada indivíduo.

3. Principais problemas da velhice

Algumas alterações biológicas esperadas no idoso com o envelhecimento podem ocorrer independente da vontade e da idade do idoso, ocorre naturalmente e nem sempre o 
idoso percebe o início de seu declínio, sendo elas: Alterações no sistema cardiovascular, Arteriosclerose, Aumento da pressão arterial, Diminuição da função pulmonar, Envelhecimento músculo-esquelético, perda da massa muscular, Osteoporose, alterações no sistema nervoso central, envelhecimento psicológico e social;

Para Shephard (2003) dificuldades com a cognição, aprendizagem de novas tarefas e memória de curto prazo são devido ao envelhecimento do cérebro. O mesmo autor expressa que "o ritmo de aprendizado torna-se mais lento em uma pessoa idosa, e uma abordagem mais simples leva a uma redução no aprendizado dos elementos periféricos de uma tarefa".

Para Shephard (2003) dificuldades com a cognição, aprendizagem de novas tarefas e memória de curto prazo são devido ao envelhecimento do cérebro.

Shephard (2003, p. 117) expressa que "o ritmo de aprendizado torna-se mais lento em uma pessoa idosa e uma abordagem mais simples leva a uma redução no aprendizado dos elementos periféricos de uma tarefa. E a extensão da perda funcional pode ser ilustrada por mensurações, tais com o desempenho de grandes mestres de xadrez, que comumente atingem o seu máximo por volta dos 35 anos.”

Dificuldades para recordar nomes, números de telefones e objetos guardados são as recordações de memória que mais chamam a atenção das pessoas idosas, pois estas temem que as perdas possam evoluir para um possível quadro de demência (Canineu; Bastos, 2002).

Assis (2004), o envelhecimento e suas alterações de saúde levam o idoso ao estreitamento da sua inserção social. As alterações físicas, como perdas sensoriais (déficit auditivo e visual), déficits cognitivos, problemas osteoarticulares, seqüelas ou descontrole de doenças crônicas, são fatores que limitam a mobilidade e a independência do idoso, prejudicando sua sociabilidade, atividades diárias e bem-estar.

Para Affiune (2002), o envelhecimento estabelece algumas modificações estruturais, pois, este leva à diminuição da reserva funcional, estabelecendo um limite para a performance durante a atividade física.

Desta maneira, o exercício pode modificar alguns processos fisiológicos que diminuem com a idade, melhorando a eficiência cardíaca, a função pulmonar e os níveis de cálcio (Hayflick, 1997).

Shephard também (2003) afirma que, com o envelhecimento, os ossos dos idosos tornam-se progressivamente mais vulneráveis a fraturas, pois mostram uma perda progressiva, tanto de minerais quanto de matriz óssea. 
Pacheco (2005) considera a aposentadoria "um rito de passagem para a velhice, ela acentua sua vinculação à terceira idade, numa sociedade de consumo na qual apenas o novo é cultuado como fonte da renovação, do desejo, da posse" (p. 65). Debert (1999) possui outro entendimento à medida que não considera a aposentadoria uma passagem para a velhice. Para essa autora, a aposentadoria deixou de ser um momento de descanso e recolhimento e tornouse um período de atividade e lazer. Mais uma vez, percebe-se o quanto a velhice é uma experiência heterogênea e complexa, pois para alguns a aposentadoria pode significar o desengajamento da vida social e, para outros, o início de uma vida social prazerosa, composta por atividades e lazer.

Para Rossi e Sader (2002), um dos primeiros sinais da velhice é a menor capacidade de trabalho. Essa menor capacidade afeta em última instância a capacidade laboral, a adaptabilidade ao ambiente e a atividade motora. Os exercícios físicos, no entendimento de Rossi e Sader (2002), melhoram tal função muscular, diminuindo a frequiência de possíveis quedas e contribuindo para melhor qualidade de vida dos idosos. Assim, exercícios realizados de forma contínua no decorrer de toda a vida podem atuar como fatores preventivos em muitas deficiências relacionadas à idade. Bom exemplo são os exercícios de resistência que, além de trazerem aumento a massa muscular em ambos os sexos, propiciam a minimizações e reversão da síndrome de fragilidade física presente nos idosos.

Both (1999, p. 14) assinala que as famílias muitas vezes não estão preparadas para lidar com a vida que se estende ao longo dos anos, nem mesmo os próprios velhos sabem o que farão consigo mesmos. E é desse despreparo que surgem as dificuldades e as dúvidas sobre como lidar com o envelhecimento, o que acaba gerando concepções falsas e maldosas acerca dos velhos.

Para Zimerman (2000), o ser humano apresenta uma série de mudanças psicológicas com o envelhecimento, as quais resultam da dificuldade de adaptações a novos papéis sociais, falta de motivações, baixa-estima, auto-imagem baixa, dificuldade de mudanças rápidas, perdas orgânicas e afetivas, suicídios, somatizações, paranóia, hipocondria, depressão.

Assis (2004) afirma que a prática regular de exercício físico no idoso contribui para o controle da depressão e diminuição da ansiedade, possibilitando a este maior familiaridade com o seu corpo e funções. Desta maneira, a atividade física em qualquer idade pode reduzir os riscos de depressão e declínio cognitivo (Spirduso e Cronin, 2001). 
Zimerman (2000) pensa que, ao envelhecer, é necessário aprender um estilo de vida novo, com o único objetivo de promover a minimizações das perdas que estes idosos apresentam na sociedade.

Para Assis e Araújo (2004), as mudanças fisiológicas do envelhecimento, combinadas com a inatividade física, ocasionam processos patológicos que podem levar o idoso a uma perda progressiva de autonomia e independência. Assim, idosos que se mantêm ativo ao longo da vida apresentam ganhos na saúde, com maior autonomia e independência (Cress et Al., 1999).

4. Aspectos legais de proteção ao idoso

\subsection{A Política Pública de Assistência Social ao Idoso}

A Constituição Federal de 1988 define um modelo de proteção social configurado como um sistema de seguridade social. Envolve a previdência social (elaborada nos moldes de seguro social), a assistência social (entendida como direito e não como filantropia) e a saúde. Ou seja, busca-se articular os direitos contributivos e transferências de renda não contributivas vinculadas à assistência social sob a égide dos direitos sociais. Assim, a assistência social integra o sistema de seguridade social como política pública não contributiva. É, portanto, direito do cidadão e dever do Estado.

A partir daí, a assistência social experimentou grandes avanços: promulgação da Lei Orgânica da Assistência Social (LOAS), em 1993, que a reconheceu como política pública de seguridade social, tornando-a responsável pela oferta de proteção social não contributiva à população socialmente mais vulnerável; gestão compartilhada pela implantação dos conselhos e criação dos fundos de assistência social nas três esferas de governo; elaboração dos Planos Municipais de Assistência Social (PMAS); criação de instâncias de pactuação e realização de conferências nos três níveis governamentais, as quais concretizaram grandes fóruns de discussão, participação e consensos na evolução dessa política.

A assistência social visa a garantir proteção social a todos os que dela necessitam, independentemente de qualquer contribuição prévia. Isso significa que qualquer cidadão brasileiro tem direito aos benefícios, serviços, programas e projetos socioassistenciais sem o 
caráter contributivo, o que permite eliminar ou reduzir os níveis de vulnerabilidade e/ou fragilidade social.

Os serviços da política de assistência social são balizados na centralidade da família e nos territórios. A família é percebida como sujeito estratégico no amparo social de seus membros e também como alvo prioritário de proteção.

O princípio da matricialidade sociofamiliar considera a família o núcleo social básico de acolhida, convívio, autonomia, sustentabilidade e protagonismo social do idoso.

$\mathrm{Na}$ Política Nacional de Assistência Social ocorre uma divisão de tarefas e responsabilidades, sem, no entanto, reduzir a importância das instâncias nacional, estadual e/ou municipal. A descentralização busca aproximar as respostas da União (por meio de políticas sociais) da realidade local, compreendendo as diferenças e especificidades, alvo da política de assistência social. O município, portanto, tem papel de destaque em sua operacionalização.

Na visão de Carvalho, a articulação, parceria e complementaridade para evitar ações isoladas e fragmentadas entre o Estado e a sociedade, representadas pelas organizações de assistência social, exigem uma relação democrática, horizontal, participativa e proativa - o trabalho em redes. Quando coordenadas pelo Estado, são essenciais para estruturar propostas mais abrangentes para obter resultados mais efetivos na qualidade de vida dos cidadãos (Carvalho, 2006).

Como projeto governamental de renda mínima, foi criado o Benefício de Prestação Continuada (BPC) que é um direito constitucional regulamentado pela LOAS no valor de um salário mínimo para idosos com 65 anos ou mais e pessoas com deficiência que comprovem renda familiar inferior a um quarto do salário mínimo, ou seja, sem condições de prover sua subsistência. Não se trata de uma aposentadoria ou pensão, mas de um benefício assistencial, cujo beneficiário não precisa ter contribuído anteriormente para a Previdência Social. Em mais de $70 \%$ dos casos direcionados ao sustento da família, representa, para a população idosa, o principal programa de prestação social operado por meio de transferência de renda.

Diante desse novo paradigma, as ações de assistência social dividem-se em duas categorias de atenção, de acordo com a natureza ou o tipo e complexidade do atendimento: proteção social básica e proteção social especial. Cada uma das proteções conta com equipamentos que caracterizam o direito assistencial, espaços físicos públicos onde são desenvolvidas atividades de proteção à família e ao indivíduo. 
Tem como objetivos: prevenir situações de risco social; estimular o desenvolvimento de vínculos familiares e comunitários; promover o autoconhecimento quanto à condição de vida e à relação com familiares e vizinhos, assim como a compreensão dos direitos sociais.

Configura-se como um conjunto de serviços, programas, projetos e benefícios de assistência social estruturados para atender pessoas em situação de vulnerabilidade e risco social decorrente de pobreza, apartação da sociedade, ausência de renda, fragilidade dos vínculos familiares e/ou comunitários, discriminação, entre outros. Isto é, a proteção social básica tem como foco principal a prevenção ao isolamento e ao abrigamento. As ações e os benefícios desse tipo de proteção destinados às pessoas idosas e seus familiares são: Centro de Convivência para Idosos, Benefício de Prestação Continuada (BPC), programa Bolsa Família, ações socioeducativas promovidas pelo Programa de Atenção Integral à Família (PAIF) e apoio e orientação a grupos de cuidadores de idosos.

A promoção de encontros e reuniões que estimulem a reflexão e discussão de interesse comum, principalmente no caso dos idosos, para que se possa fortalecer a malha social, rompendo com discriminações e desrespeito e estimulando, assim, o protagonismo social do idoso. Essa participação previne riscos sociais relacionados ao ciclo de vida, como o isolamento e o asilamento, que muitas vezes levam a pessoa idosa a quadros depressivos, à demência e mesmo à morte.

Os idosos com algum grau de dependência, a PNAS promove ações de atenção individualizada e personalizada em domicílio, de caráter preventivo e de garantia de direitos. $\mathrm{O}$ atendimento caracteriza-se pelo apoio ao idoso e a sua família, identificado pelas equipes do CRAS, que em uma ação integrada com outras políticas públicas atendem a pessoa idosa, na perspectiva da permanência no domicílio.

É um conjunto de serviços, programas e projetos que tem por objetivo prestar atendimento especializado a famílias e indivíduos em situação de risco pessoal e social e violação de direitos, visando ao fortalecimento de suas potencialidades e a sua proteção. No caso da pessoa idosa, tal situação pode ter sido causada por abandono, violência física ou psicológica, abuso sexual ou negligência. A proteção social especial está focada na defesa da dignidade e dos direitos do idoso, monitorando a ocorrência dos riscos e de seu agravamento e oferecendo serviços de acolhimento.

\subsection{A Lei ${ }^{\circ} 10741 / 03-$ Estatuto do Idoso}


O Estatuto do Idoso foi instituído visando regular os direitos assegurados às pessoas com idade igual ou superior a sessenta anos.

Em seu art. $2^{\circ}$ ficou estabelecido que o idoso goza de todos os direitos fundamentais inerentes à pessoa humana, sem prejuízo da proteção integral de que trata esta lei, assegurando-se-lhe, por lei ou por outros meios, todas as oportunidades e facilidades, para preservação de sua saúde física e mental e seu aperfeiçoamento moral, intelectual, espiritual e social, em condições de liberdade e dignidade.

Através desses artigos podemos verificar a preocupação do legislador em manter a qualidade de vida dos idosos e assegurar a eles condições básicas de sobrevivência.

No art. $3^{\circ}$ do estatuto ficou estabelecida a obrigação da família, da comunidade, da sociedade e do poder público assegurar ao idoso, com absoluta prioridade, a efetivação do direito à vida, à saúde, à alimentação, à educação, à cultura, ao esporte, ao lazer, ao trabalho, à cidadania, à liberdade, à dignidade, ao respeito e à convivência familiar e comunitária.

Através do Estatuto do Idoso, ficou estabelecida a prioridade dos idosos nos seguintes aspectos:

- Atendimento prioritário;

- Formação de Políticas Públicas;

- Destinação de recursos públicos para a manutenção de projetos;

- Viabilização de formas alternativas de participação, ocupação e convívio do idoso com as demais gerações;

- Priorização do atendimento do idoso por sua própria família, em detrimento do atendimento asilar, exceto dos que não a possuam ou careçam de condições de manutenção da própria sobrevivência;

- Capacitação e reciclagem dos recursos humanos nas áreas de geriatria e gerontologia e na prestação de serviços aos idosos;

- Divulgação de informações de caráter educativo sobre os aspectos biopsicossociais de envelhecimento;

- Garantia de acesso à rede de serviços de saúde e de assistência social locais;

- Prioridade no recebimento da restituição do imposto de renda. 
Os artigos. $4^{\circ}$ e $5^{\circ}$ do estatuto prevêem a proteção dos idosos contra qualquer tipo de negligência, discriminação, violência, crueldade ou opressão, e todo atentado aos seus direitos, por ação ou omissão, devendo o responsável ser punido na forma da lei.

Na mesma linha os artigos 10 a 19 dispõem sobre o Direito à Liberdade, ao Respeito e à Dignidade do idoso, englobando:

- O direito a liberdade - direito de ir e vir;

- O direito a garantia dos alimentos;

- O direito a saúde, gratuita, através do Sistema único de Saúde, assegurando inclusive a assistência de um familiar em caso de internação;

- O direito a educação, cultura, esporte, lazer, diversões, espetáculos, produtos e serviços que respeitem sua peculiar condição de idade.

- o idoso tem direito a profissionalização e ao exercício de atividade profissional, respeitadas suas condições físicas, intelectuais e psíquicas, não sendo permitida a discriminação e a fixação de limite máximo de idade.

- Direito a previdência social;

- Direito a assistência social.

O Legislador em seu Título III, estabeleceu as medidas protetivas aos idosos; no Título IV ficou estabelecida a Política de Atendimento ao Idoso, as normas para os estabelecimentos de atendimento ao idoso e também as penalidades pelo não cumprimento do estabelecidos na presente lei.

O Título $\mathrm{V}$ trata do acesso a justiça, sendo essa prioridade no caso dos idosos, visando a proteção ao exercício do direito e dos seus interesses.

Através dessa análise podemos verificar a importância do Estatuto do Idoso para a garantia dos direitos dos idosos, o advento dessa lei trouxe uma grande evolução na legislação e nas normas para a manutenção do bem-estar e da qualidade de vida na terceira idade.

5. Aspectos sociais do envelhecer com qualidade de vida 
Envelhecer com saúde, autonomia e independência, por mais tempo possível, constitui hoje, um desafio à responsabilidade individual e coletiva, com grande preocupação no desenvolvimento econômico dos países.

Estudos atuais desenvolvem sobre a temática da esperança de vida com e sem incapacidade. O objetivo consiste, então, em avaliar as conquistas quantitativas em anos de vida com saúde. Os resultados apontam para diferenças importantes entre homens e mulheres. $\mathrm{O}$ autor destaca ainda o fato de os primeiros, cujo limiar de esperança de vida à nascença é inferior ao das mulheres, usufruirem de mais elevada esperança de vida sem incapacidade (Fernandes, s.d.).

O conceito de envelhecimento ativo foi preconizado pela Organização Mundial de Saúde e defendido na II Assembléia Mundial sobre o Envelhecimento (2002). Este conceito depende de uma variedade de influências, ou determinantes, que envolvem não apenas os indivíduos, como as famílias e as próprias nações. De acordo com a Organização Mundial da Saúde - OMS, o envelhecimento ativo é o processo de otimização das oportunidades de saúde, participação e segurança.

A OMS (1998) definiu qualidade de vida como a percepção do indivíduo da sua posição na vida, no contexto da cultura e sistema de valores nos quais se insere e em relação aos seus objetivos, expectativas, padrões e preocupações.

O envelhecimento bem-sucedido, segundo a maior parte das abordagens, envolve a perspectiva de indivíduo ativo e participativo na comunidade em que se insere. Assim, envelhecer de modo bem-sucedido envolve a definição de um novo projeto de vida com objetivos adequados e apropriados às suas novas exigências.

Segundo Salvador-Carulla (2004) o envelhecimento ativo envolve aspectos tais como: a promoção da saúde, o ajuste físico e a prevenção da incapacidade; a otimização e compensação das funções cognitivas; a promoção do desenvolvimento afetivo e da personalidade, e ainda, a maximização do envolvimento social do individuo.

No idoso a qualidade de vida pode ser percebida como boa ou ruim de acordo com a forma como cada indivíduo vivencia a velhice, podendo variar entre os dois extremos (muito bom e péssimo). Nesse sentido, a qualidade de vida depende da interpretação emocional que cada indivíduo faz dos fatos e eventos e está intimamente relacionada à percepção subjetiva dos acontecimentos e condições de vida. (Xavier, 2003).

Assis (2004) afirma que a prática regular de exercício físico no idoso contribui para o controle da depressão e diminuição da ansiedade, possibilitando a este maior familiaridade 
com o seu corpo e funções. Desta maneira, a atividade física em qualquer idade pode reduzir os riscos de depressão e declínio cognitivo (Spirduso e Cronin, 2001).

Estudos atuais sugerem que os idosos podem apresentar uma imensa capacidade de se adaptar a novas situações e de pensar estratégias que sirvam como fatores protetores.

A hierarquia entre os componentes é representada pela integridade das funções física e mental. Essas funções atuam como potencial para a realização das atividades sociais, envolvendo as relações interpessoais e as atividades produtivas, remuneradas ou não.

De acordo com Baltes (1987) existem três grandes categorias de influências ou de fatores determinantes para uma velhice mais ou menos bem sucedida:

1. Fatores ligados ao grupo etário (relacionados com a idade cronológica ou biológica);

2. Fatores relacionados com o período histórico em que se vive e que se designa como "efeito de corte":

3. Fatores associados à história pessoal ou aos acontecimentos autobiográficos do individuo.

Segundo o autor: Da conjugação destes três fatores ou circunstâncias resultará uma velhice mais ou menos feliz ou infeliz, podendo em determinados momentos, pesar mais um ou outro fator. (Baltes,1987)

Também Fontaine (2000) faz menção a três tipos de fatores na área pessoal determinantes para uma velhice saudável: a saúde biológica, a manutenção de um elevado nível de funcionamento cognitivo e físico e a manutenção da participação social, mesmo após a reforma.

A promoção da saúde e os cuidados de prevenção, dirigidos às pessoas idosas, aumentam a longevidade, melhoram a saúde e a qualidade de vida e ajudam a racionalizar os recursos da sociedade. Está provada a eficácia da prevenção dos fatores de risco comuns a várias patologias incapacitantes de evolução prolongada, pelo que é prioritária uma ação concertada, de todos os atores da sociedade, para melhorar os cuidados com uma boa nutrição, desincentivar o consumo de excesso de álcool, a cessação ou redução do consumo de tabaco, a prática regular de atividade física e o controlo dos fatores de stress.

A qualidade de vida tornou-se, assim, na década de 80, um conceito de interesse geral e de senso comum, dado que, a maneira como cada um imagina e infere a qualidade de vida não é a mesma nem quanto aos conteúdos a focar, nem quanto ao modo de avaliar. Neste sentido, 
formularam-se várias definições de qualidade de vida ao longo dos anos, desde a avaliação pessoal e global dos bens e das características satisfatórias de vida, até ao nível da satisfação das necessidades físicas, sociais, psicológicas, estruturais e materiais do indivíduo (Rodrigues, 1991).

A qualidade de vida parece estar relacionada com o grau de satisfação que o indivíduo sente pela vida, tal qual, como vimos anteriormente é um conceito multidimensional e que na idade avançada adquire novas complexidade.

Donald (1997, cit. in:. Jacob, 2007) tentou definir o conceito de qualidade de vida para idosos e formulou cinco classes que tanto pode servir de referência para os mais velhos, como para os profissionais que os atendem:

- Bem-estar físico;

- $\quad$ Relações Interpessoais (família, amigos e participação na comunidade);

- Desenvolvimento pessoal;

- Atividades espirituais e transcendentais;

- Atividades recreativas (socialização, entretenimento ativo e passivo)

Para envelhecer com melhor qualidade de vida o idoso deve apresentar alguns aspectos descritos a seguir: independência funcional, satisfação com a vida, equilíbrio social, apoio por parte dos que lhe são próximos e níveis adequados de qualidade de vida.

\section{Considerações Finais}

Através desse trabalho pudemos verificar que a representação social do envelhecimento vem sofrendo muitas mudanças ao longo das últimas décadas.

Vários problemas são enfrentados com o envelhecimento, aspectos biológicos, sociais e psicológicos interferem diretamente no cotidiano e no bem-estar do idoso.

Com o envelhecimento da população foi necessário que se estabelecesse uma legislação que visasse assegurar o bem-estar e também que fomentasse a adoção de políticas públicas de proteção e o bem-estar do idoso.

O Estatuto do Idoso pode ser considerada uma legislação de vanguarda, que teve uma preocupação com vários aspectos da vida do idoso. Para que o idoso tenha uma vida com dignidade é necessário que ele possa viver em família, sem ser alijada do convívio social. 
Os governos devem investir diretamente em políticas públicas que favoreçam a inclusão e a prática esportiva do idoso e adotar programas de prevenção de doenças, a fim de diminuir a internação e o consumo de medicamentos para doenças crônicas.

\section{REFERÊNCIA BIBLIOGRÁFICAS}

Affuine, A., Neri, Cançado, M.L. Gonzone, M.L. e S.M. Rocha (Eds); Tratado da Geriatria e Gerontologia. Rio de Janeiro. Guanabara. 2002. P. 28-32.

Almeida, T; Lourenço, M.L. Envelhecimento, amor e sexualidade: Utopia ou Realidade. Revista Brasileira de Geriatria e Gerontologia. Rio de Janeiro, v.1, Pág 101 a 113, 2007.

\begin{tabular}{lccc}
\hline Envelhecimento, erotismo e relacionamentos amorosos na velhice. & Envelhecimento.net. & Disponível & em:
\end{tabular}
www.portaldoenvelhecimento.net/pforum/aptv31.htm. Acesso: 22 de julho de 2016.

ANTUNES, Arnaldo. Envelhecer. https://www.letras.mus.br/arnaldo-antunes/1547283/ Acessado em 19/08/2016

Assis, M. Hartz, Z.M.A., Valla V.V. Programas de Promoção a Saúde do Idoso: uma revisão de literatura científica no período de 1990 a 2002. Ciência da Saúde e Coletiva. 2004.9:5578 .

Baltes, P.B., Theoretical proposition of life span developmental psychology: On the dynamics between grouth and decline. Development a psychology. 23 (5) 617-626. 1987.

Bauvoir, Simone. A velhice a realidade que incomoda. DIEFEL. São Paulo, 1976.

BRASIL. Presidência da Republica Casa Civil. Lei no 10741, 1/10/03. Estatuto do Idoso. Disponível em: www.planalto.gov.br. Acesso em:23 de maio de 2016.

Burckart apud Bauvoir, Simone. A velhice e a realidade que incomoda. DIEFFEL. São Paulo, 1976.

BOTH apud SANTIN, Janaína e BOROWSKI, Marina. O idoso e o princípio constitucional da dignidade humana (pág. 147)

Caneppele, $\mathrm{M}^{\mathrm{a}}$ Cristina Garcia de Lira. Capacidade Funcional e Qualidade de Vida de Indivíduos Idosos de Porto Alegre, 2007. Disponível em: http://www.dominiopublico.gov.br/pesquisa/DetalheObraForm.do? select_action=\&co_obra=1 06700 obra=106700. Acesso em: 15 julho 2016; 
Canineu P.R. e Bastos, A. Transtorno Cognitivo leve. In E.V. Freitas, L. PY, A.L. Neri, F.A.X. Cançado. M.L. Gonzoni, S.M. Rocha (Eds). Tratado da Geriatria e Gerontologia. Rio de Janeiro. Guanabara, 2002.

$\begin{array}{llll}\text { Declaração universal } & \text { dos } & \text { Direitos } & \text { Humanos }\end{array}$ http://www.direitoshumanos.usp.br/index.php/Declara\%C3\%A7\%C3\%A3o-Universal-dosDireitos-Humanos/declaracao-universal-dos-direitos-humanos.html Acesso em 19/08/2016

Donald (1997) apud Jacob (2007). Animação de Idosos. Porto Âmbar.

Estatuto do Idoso. http://www.planalto.gov.br/ccivil_03/leis/2003/L10.741.htm Acesso em $19 / 08 / 2016$

Fernandez_Ballasteros, R. Active Aging: The contribuition of psycology. Cambridge, MA: Hogrefe\&Huber Publishers. 2008.

Fonteine R. Psicologia do envelhecimento. (tradução de José Almeida) Lisboa. CLimepsi Editores. 2000.

Gomes, Sandra; Munhol, Maria Elisa; Dias, Eduardo; [coordenação geral Áurea Eleotério Soares Barroso] Políticas públicas para a pessoa idosa : marcos legais e regulatórios. -- São Paulo : Secretaria Estadual de Assistência e Desenvolvimento Social : Fundação Padre Anchieta, 2009.

Hayfluk, L. Como e porque envelhecemos. Rio de Janeiro. Campus, 2000.

Hoyer, W.J. Roodin, Adult development and aging. New York. The Mc Graw - Hill . 2003.

IBGE http://www.ibge.gov.br/apps/populacao/projecao/ Acesso em 19/08/2016

Moragas, R. Gerontologia social: envelhecimento e qualidade de vida.São Paulo. Paulinas.1997.

Oréfice, José Luís Feltrin, Qualidade de Vida e Dor Física em Idosos, 2007. Disponível em:http://www.dominiopublico.gov.br/pesquisa/DetalheObraForm.do?select_action=\&co_obr $\mathrm{a}=60348$. Acesso em: 14 de julho de 2016;

Organização Mundial de Saúde - OMS. Enrijecimento y salud. 55 . Asamblea Mundial de La Salud. A 55/17. 2002.

Organização Mundial de Saúde (OMS) - ENVELHECIMENTO, www.who.int/es/index.html. Acesso: 29 de julho de 2016.

Organização Mundial de Saúde. Apresenta texto sobre promoção e saúde . Glossário. Genebra. 1998. 
Salvador- Carulla L., Cano Sanchez, A., Cabo, Soler J. Longevidad: Tratado Integral sobre a salud em la segunda nutad de La vida. Madrid, Editorial Médico. Panamericana. 2003.

Schneider, Rodolfo e Irigaray, Tatiana. O envelhecimento na atualidade: aspectos cronológicos, biológicos e sociais. Revista Estudos da Psicologia. Campinas. 2008.

Shephard, R.J. Envelhecimento, atividade física e saúde. São Paulo, Phorte, 2003.

Rossi, E. E Sader, C.S. Envelhecimento do sistema osteoarticula. In E.V. Freitas., L. Py., A.L. Néri., F.A.X. Cançado., M.L. Gorzoni, M.L e S.M. Rocha (Eds.), Tratado de Geriatria e Gerontologia. Rio de Janeiro: Guanabara Koogan. p.508-514, 2002.

Spircluso W.W. e Cronin D.L. Exercise dose-response e effects on living in older adultas. Medicine and Science in Sports and Exercise, V. 33, N6, p 598-608. 2001.

Xavier, F.M. Episódio depressivo maior, prevalência e impacto sobre qualidade de vida, sono e cognição em octogenários. Disponível em: http://www.scielo.br/ Acesso em: 26 de maio de 2016. São Paulo.

BIBLIA SAGRADA. Tradução dos originais pelo Centro Bíblico Católico, revista por Frei João José Pedreira Castro. Editora Ave Maria, 97ª Edição, São Paulo, 1995. (pág.1519) (pág. 187-188)

Zimerman, G.I. Velhice: aspectos biopsicossociais. Porto Alegre. Artes Médicas Sul, 2000. 